\title{
Using Photogrammetric UAV Measurements as Support for Classical Topographical Measurements in Order to Obtain the Topographic Plan for Urban
}

\section{Areas}

\author{
Elemer-Emanuel SUBA ${ }^{1}$, Tudor SĂLĂGEAN ${ }^{2 *}$, Ioana POP², Florica MATEI ${ }^{2}$, \\ Jutka DEAK ${ }^{2}$, Iulia COROIAN ${ }^{2}$ and Diana FICIOR ${ }^{2}$ \\ ${ }^{1}$ Department of Topography and Cadastre. Technical University of Civil Engineering, 124 Lacul Tei \\ Boulevard, 020396 București, Bucharest, Romania. \\ ${ }^{2}$ Department of Land Measurements and Exact Sciences, University of Agricultural Sciences and \\ Veterinary Medicine, 3-5 Mănăștur St. 400372 Cluj-Napoca, Romania \\ *Corresponding author, e-mail: tudor.salagean@usamvcluj.ro
}

Bulletin UASVM Horticulture 74(2)/ 2017

Print ISSN 1843-5254, Electronic ISSN 1843-5394

DOI:10.15835/buasvmcn-hort: 0026

\begin{abstract}
This article aims to highlight the benefits of UAV photogrammetric measurements in addition to classical ones. It will also deal with the processing and integration of the point cloud, respectively the digital elevation model in topo-cadastral works. The main purpose of this paper is to compare the results obtained using the UAV photogrammetric measurements with the results obtained by classical methods. It will briefly present the classical measurements made with the total station. In the present project, the closed-circuit traverse and the supported on the endings traverse were made using known coordinate points. Determining the coordinates of the points used for the traverses was done by GNSS methods. The area on which the measurements were made is $67942 \mathrm{~m}^{2}$ and is covered by 31 determined station points. From these points, 13 were used as ground control points, respectively components of the aero-triangulation network and 17 points were used to control the obtained results by comparing their coordinates obtained by classical methods with those obtained by the UAV photogrammetric method. It was intended that the constraint points of the aero triangulation to be uniformly distributed on the studied surface.
\end{abstract}

Keywords: photogrammetric measurements, point cloud, topographical plan, UAV

\section{INTRODUCTION}

In the close past, the development of cheap high quality digital cameras and the computation power of personal computers has led to rebirth of what was once "the old cartographic dream" of modelling the world in 3D.

With UAV photogrammetric technology, topocadastral panelling is becoming a relatively easy task. Of course, as all the emerging technologies have to be tested, constantly improved, but especially to gain the attention to gain the trust of specialists in the field, it has to be tested compared to classical methods. The main purpose of this article is to identify the main advantages and disadvantages of UAV photogrammetry technology compared to classical methods. (Popescu, 2009; Popescu, 2010) We ask ourselves to analyse both from the efficiency point of view, in terms of time spent in the field, but also from the point of view of precision.

For geomatics applications, the first experiences were carried out by Przybilla and WesterEbbinghaus (1979). In the last years, more and more applications of UAVs in the geomatics field became common (Remondino et al., 2011).

UAV photogrammetry indeed opens various, new applications in the close range aerial domain and introduces also a low-cost alternatives to 
the classical manned aerial photogrammetry (Colomina et al., 2008).

Classical aerial-photogrammetry has existed for a very long time and has been applied in various areas, but it has several disadvantages over UAV methods. The main advantages of UAV technology compared to classic methods are: UAV technology does not require a human pilot and therefore can also be used in areas with different natural risks, not endangering the life of the pilot; Can be used at low latitudes, where a classic aircraft would be too risky to fly; Is clearly superior in terms of the quality/price ratio, the prices of a UAV system cannot be compared to those of a classic system; and so on. The main steps for making UAV photogrammetric elevations are: establishing the area of interest and the desired precision (land recognition); Making the flight plan; Marking ground control points and determining them by classical methods; Performing the actual flight and collecting the data (photograms), respectively, the processing and exploitation of the collected data in order to integrate them into the current works (Vorovencii, 2010).

\section{MATERIALS AND METHODS}

The following tools were used in this paper: Total Station South NTS 665 - for classical determinations, Two SOUTH S82V dual frequency GNSS receivers and a Phantom3 Advanced DJI Phantom3 Advanced with radio and PDA, which has a 12 mpixel sensor and a 40003000 resolution.

For the GNSS determinations the base-roverradar measurement method has been adopted. The devices used for making GPS measurements by the base-rover method were two SOUTH S82-V double-frequency receivers that provide measurement on Real Time Kinematic (RTK) mode $8 \mathrm{~mm}+1 \mathrm{ppm}$ RMS horizontally, $15 \mathrm{~mm}+$ $1 \mathrm{ppm}$ RMS on elevations. As reference for the rover was used a base station determined by long-time averaging. To determine the base point, we obtained the following RMS: $0.0053 \mathrm{~m}$ on $\mathrm{X}$, $0.0020 \mathrm{~m}$ on $\mathrm{Y}, 0.0031 \mathrm{~m}$ on $\mathrm{Z}$.

Polygonal route method and sideshots method using South NTS 665 Total Station: Two closedloop routing and three routing with known and end-to-end guidance on known coordinate points, these points being determined with GPS South $\mathrm{S}$ 82-V through the above mentioned method. Figure 2 shows the poligonal routes used in classic methods. The shape of these polygonal routes, but also the large number of station points is due to the configuration of the land, respectively the obstacles encountered, the area being an urban, occupied by many blocks.

After the classical measurements, the station points were marked by the asphalt painting. These points served both as ground control points and checkpoints for the results.

A next step is flight planning, being one of the most important stages of UAV photogrammetry. At this stage, several important elements are identified, such as:

The image scale factor is defined by the flight height above ground $\mathrm{Hg}$ and the focal length of the camera systems:

$m_{b}=\frac{H_{g}}{f}$

where:

$\mathrm{m}_{\mathrm{b}}$ - image scale factor;

$\mathrm{H}_{\mathrm{g}}$ - flight height;

$\mathrm{f}-$ focal length.

The ground distance of an image side can be calculated with $S^{\prime}$ or s' respectively if an analogue or digital camera is used:

$S=\frac{S^{`} \cdot H_{g}}{f}$

The length of the baseline is given with $\mathrm{p} \%$ forward overlap

$B=S\left(1-\frac{p}{100}\right)$

and the distance between two neighbouring flight lines with $\mathrm{q} \%$ side lap can be calculated

$\alpha=S\left(1-\frac{p}{100}\right)$

The covered model area is product of

$F_{m}=S^{2}-S \cdot B$

where:

S - image format (digital/analog);

$S^{\prime}$ - side of the photogram on the terrestrial surface;

B - base of aerial-photography;

- the length of the aerophotographic base for

longitudinal coverage;

$\mathrm{F}_{\mathrm{m}}$ - stereoscopic model surface. 


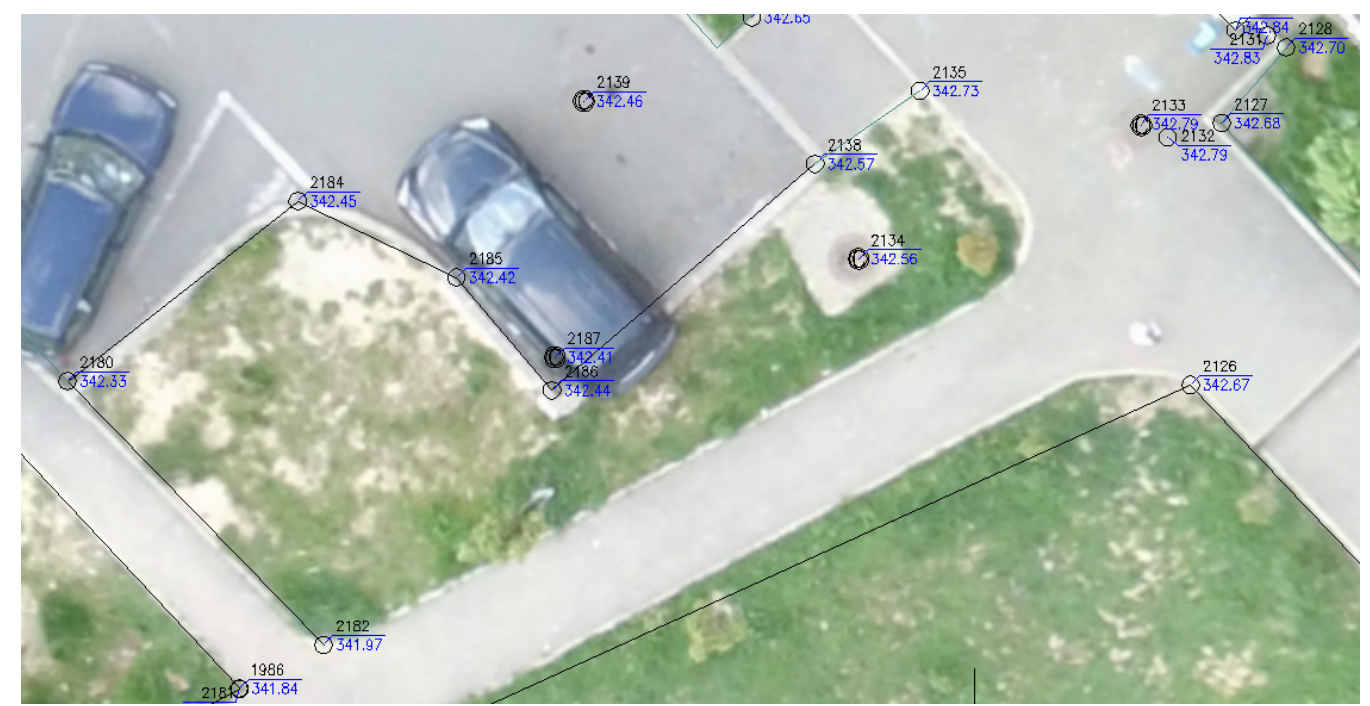

Fig. 1. Classical topographic elevations overlapping with orthophotomap obtained by UAV methods

The image scale factor equation is just a rough estimate for the covered area by a flight.

The expected accuracy in height can be calculated with the measurement accuracy in planimetry sx and the ratio of flight height and baseline in image space, while $\mathrm{sx}$ is defined through the measurement method and the pixel size (px) (Eisenbeiss, 2009). Manually measured points can be defined with an accuracy as low as to 0.5 Pixel, while automatic measurement methods allow an accuracy of down to 0.1 Pixel for natural targets for flat terrain and good texture (Heipke, 1999). In alpine areas the point measurement accuracy increases to 0.5 Pixel (Kersten, 1999). However, for UAV images it can be expected to achieve approximately 0.5 Pixel. The accuracies then calculate as:

$$
\begin{aligned}
& s_{x}=s_{x(\text { Mes })} \cdot p_{x} \\
& s_{z}=s_{x} \cdot \frac{H_{g}}{b}
\end{aligned}
$$

where:

$\mathrm{s}_{\mathrm{x}}$ - expected accuracy on planimetry;

$\mathrm{s}_{\mathrm{x}(\mathrm{Mes})}$ - measurement accuracy in panimetry;

$\mathrm{p}_{\mathrm{x}}$ - pixel size;

$\mathrm{s}_{\mathrm{z}}$ - expected accuracy on elevation;

$\mathrm{b}$ - base line in image space.

The triangulation method for multi-view images was bundle adjustment. Root mean square error (RMSE) was used as accuracy measurement for the photogrammetrical triangulation.

\section{RESULTS AND DISCUSSIONS}

In the following we will present both planumetric and altimetric precisions obtained by classical methods, butalso byUAV photogrammetric methods. In figure 2 , we observe the trips made by classical methods. With a relatively large number of stations, and polygonal routes with irregular trails, the precisions obtained were not indescribable. The standard deviations for each station were also presented. The biggest problem with classical lifting is the fact that certain points of detail can easily be gripped, or mistakenly merge the points by code, mistakes eliminated by the UAV photogrammetric method. In figure 1 you can observe these omissions/errors mentioned above.

Considering the terrain configuration, the measurement errors, but also the large number of stations that could not be targeted more than the upper part of the prism due to the vegetation, the deviations of the points are quite large.

Using classic methods, we have standard deviations of up to $14 \mathrm{~cm}$. These points were not used in photogrammetric processing to avoid errors. If we had to use them for processing, they were redetermined using GPS technology, with a long time averaging receiver, determined statically, using as base point the GNSS EUREF Baia 3.1 reference station and a rover connected by radio to the base point (Fig. 3).

Figure 4 shows the area under study, the flight altitude, the flight path, the beginning and end of the mission. Here too you can see the setting 


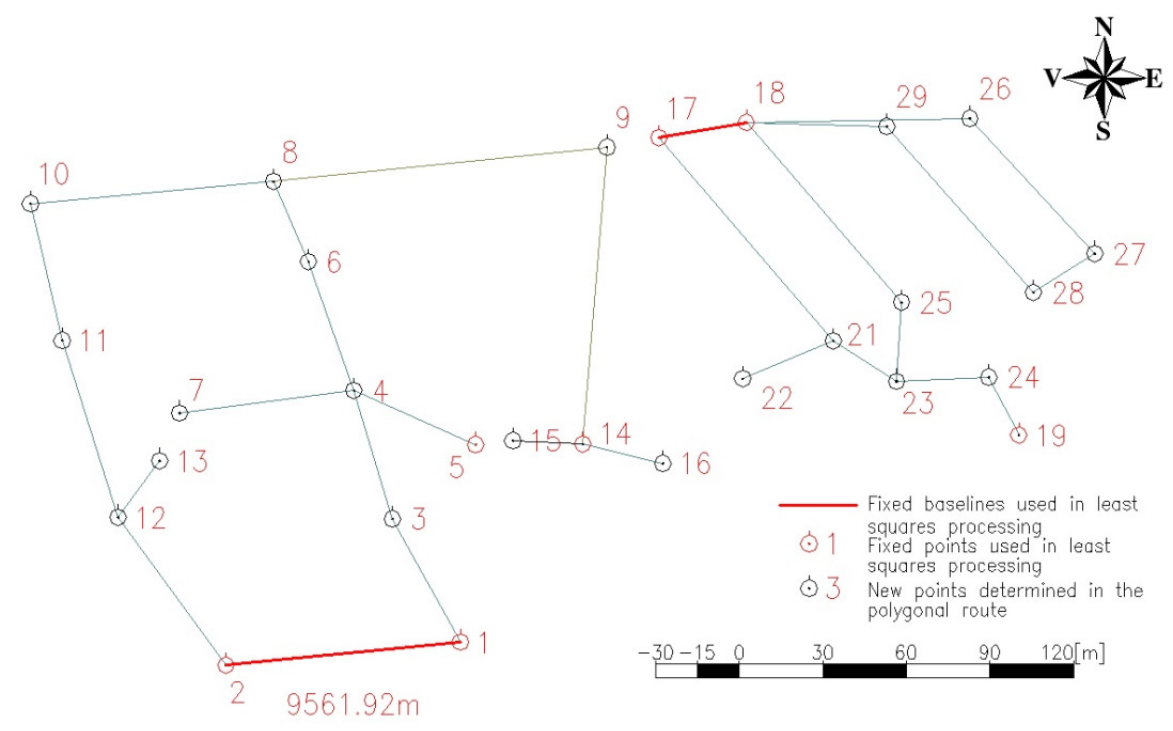

Fig. 2. Station points and the polygonal routes

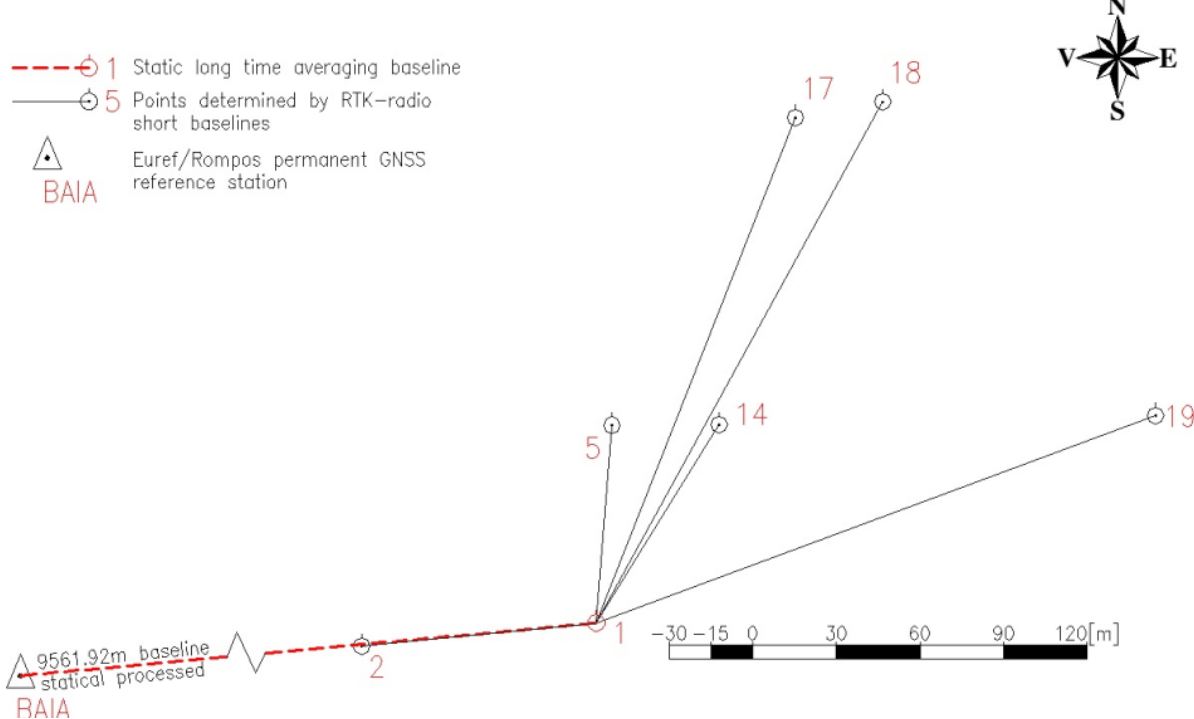

Fig. 3. GPS network

for camera orientation, front and side overlap between the photograms, flight speed and other camera states. All these settings are automatically uploaded to the drones memory, and it will fly and capture the images autonomously. Also, the landing is done independently, at the starting point (homepoint). Of course, given the GPS accuracy built into the drones, this landing is within a radius of about 1-1.5 meters, which is why it is recommended to take off / landing in open areas.

This soft is an application for the tablet, developed by Pix4D and it is open source.

After the flight planning and the flight, the photos were downloaded and processed. The data acquired by the drone is shown in figure 5 . It can be seen that the area under study is covered by over 9 photograms at each point. Only in the adjacent areas the coverage is lower, but this does not influence us because there are no determinations in that area. The black dot, which corresponds to the position of the captured images, is seen in the image.

A Phantom 3 Advanced DJI drone was used. Acquisition of photos was done automatically using specialized software. It was intended to ensure the overlapping of $80 \%$ and lateral frontal images, over $70 \%$ over the studied area. The 

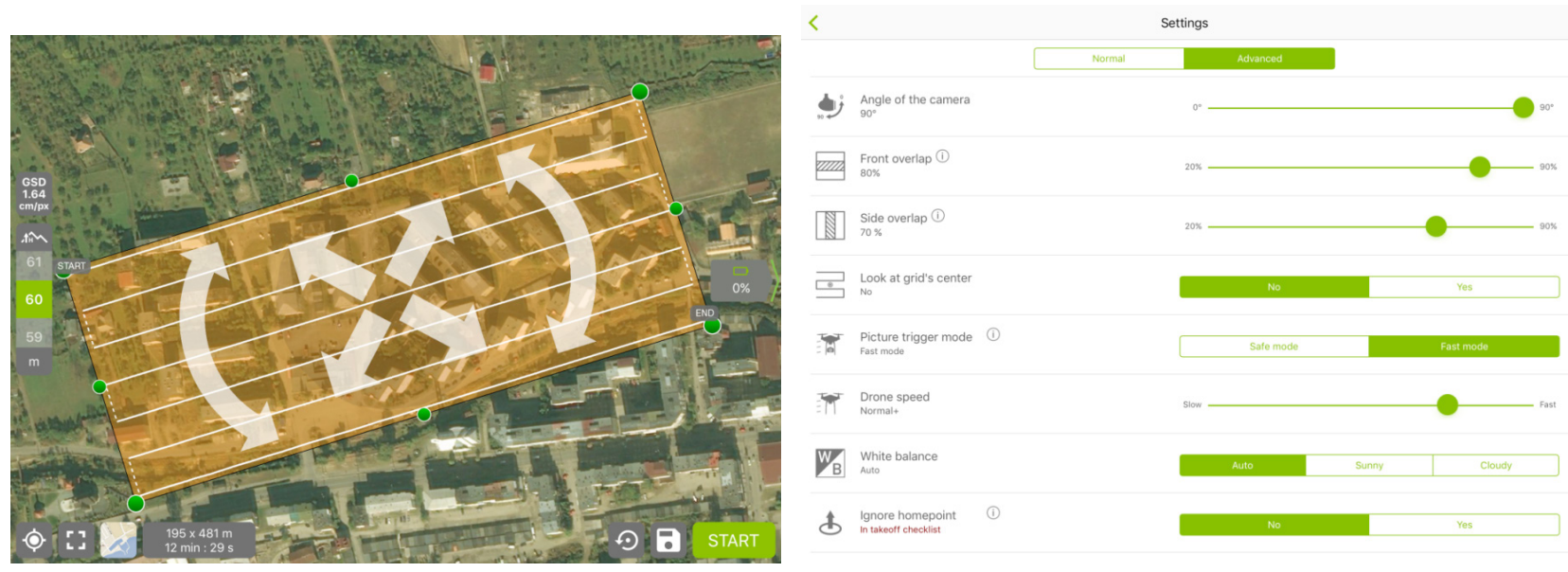

Fig. 4. UAV flight planning and settings

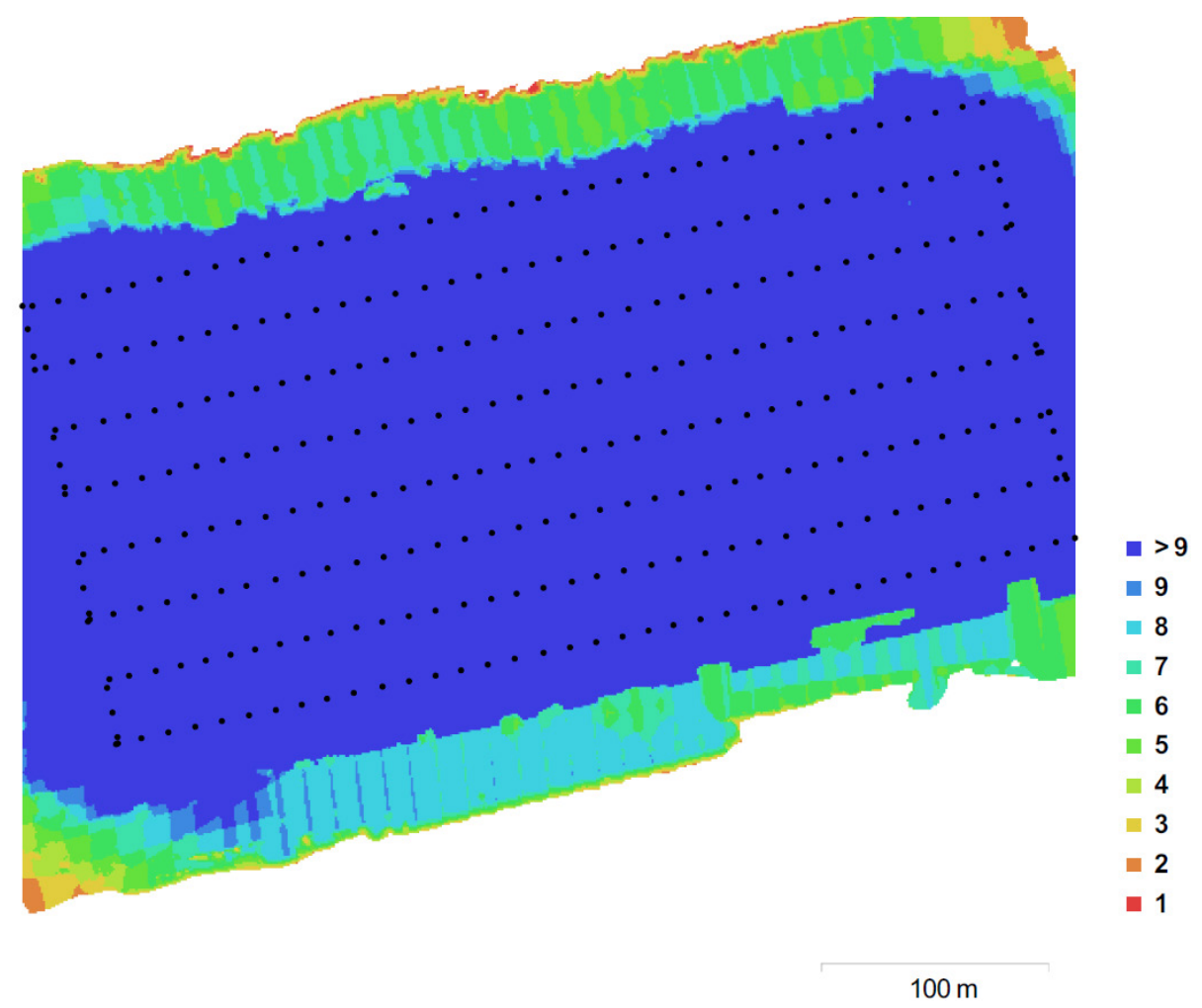

Fig. 5. Number of images taken over by UAV methods

average flight altitude was 60 meters, and 326 images were obtained.

Following processing, a ground resolution of $3.23 \mathrm{~cm} \mathrm{/} \mathrm{pixel} \mathrm{was} \mathrm{obtained,} \mathrm{and} \mathrm{the}$ average redraw error was 1.51 pixels. Ground control was performed based on station points determined by routing or GPS. As points of ground control, respectively points of constraint of the aerotriangulation were used: $1,2,5,8,9,14,19$, $21,23,24,26,27,30$, distributed uniformly on the studied area.
The planimetric standard deviation of the aerotriangulation was $0.00240045 \mathrm{~m}$, the altimetric standard deviation was: $0.00178433 \mathrm{~m}$, and the standard deviation of identifying the control points on the photograms was: 0.30 pixels. To control the results obtained, points $3,4,6,7$, $10,11,12,13,15.16,17,18,22,25,28,29,31$ were used. The digital elevation model obtained has a resolution of $5.57 \mathrm{~cm} /$ pixel, and a density of 321848 points per square meter. 

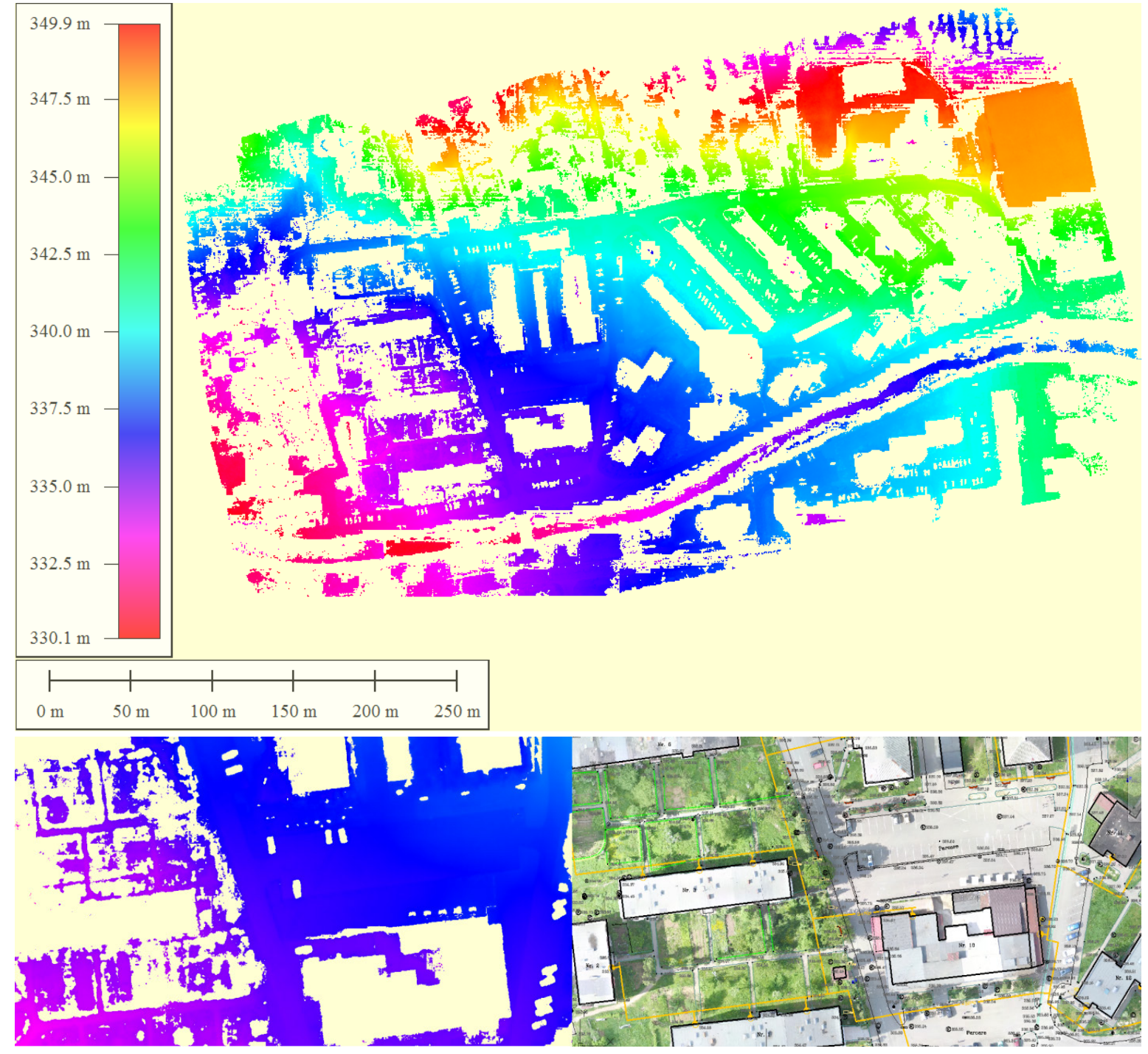

Fig. 6. Filtering the points in the point cloud

Being interested in making a situation plan, from the UAV cloud point, we filtered only those soil-specific points. This operation is done automatically by means of specialized software.

Figure 6 shows this filter. The degree of fidelity with which the software filters the data is observed. In the western part there are the alleys that have kept them and besides them the hedges and the vegetation removed from the cloud of points. Also, the buildings and the fittings have also been eliminated.

The software is capable of automatically identifying and eliminating all the points that do not match the natural tendency of the field. It is noticeable that at the bottom of the image 5 were removed the characteristic features of the vegetation, the parked cars, the sun umbrellas etc.
Having the ability to filter points, we could determine altitudes for characteristic points. The lines that distinguish the characteristic points were taken from the orthophotoplan, and their shares on the 3D model generated from the fence points represent the natural ground.

\section{CONCLUSIONS}

The use of UAV photogrammetric technology represents a great advantage in urban topocadastral works. Of course, this technology has its limitations and precisions, but in open areas with minor vegetation it is a method of making plans that should not be neglected.

The work presented in this article, the UAV photogrammetric measurements lasted 60 minutes with the marking and determination of 
the ground control points, and the processing and interpretation of the results was done within 8 hours. Compared to the classical method, which took 4 days (32 hours) for a team of 2 people on the ground and then 2 days (16 hours) for data processing in the office, the UAV photogrammetric method is clearly superior from the point of view of productivity.

Also, by the classical method, certain points were omitted, or the measurements were mistakenly combined, which is why the UAV photogrammetric method is a great advantage.

of course, classical methods are not to be left, especially in areas with dense vegetation, where no ground details can be determined. In our opinion, the UAV photogrammetry method represents the future of topo-cadastral elevations, especially in crowded urban areas, at least not as an independent method, as a back-up for classical measurements.

\section{REFERENCES}

1. 1. Colomina I, Blázquez M, Molina P, Parés ME and Wis M (2008). Towards a new paradigm for high-resolution lowcost photogrammetry and remote sensing. IAPRS\&SIS, Vol. 37(B1), Beijing, China.

2. 2. Eisenbeiss H (2009). ETH Zurich 2009, UAV Photogrammetry - doctoral thesis.

3. 3. HeipkeC (1999). Automatic Aerial Triangulation: Results of the OEEPE-ISPRS Test and Current Developements, in Wichmann, Photogrammetric week.

4. 4. Kersten $\mathrm{T}$ (1999). Digital Aerial Triangulation in Production - Experiences with Block Switzerland, in Wichmann, Photogrammetric week.

5. 5. Popescu G (2009). Sisteme interactive de modelare a informaţiilor fotogrammetrice, Matrix Rom Publishing House, Bucharest, Romania.

6. 6. Popescu G (2010) Fotogrammetria pe înțelesul tuturor, Matrix Rom Publishing House, Bucharest, Romania.

7. 7. Remondino F, Barazzetti L, Nex F, Scaioni M, Sarazzi D (2011). UAV Photogrammetry for Mapping and 3D Modeling.

8. 8. Vorovencii I (2010). Fotogrammetria, Matrix Rom Publishing House, Bucharest, Romania. 